\title{
Akupunktur erlaubt?
}

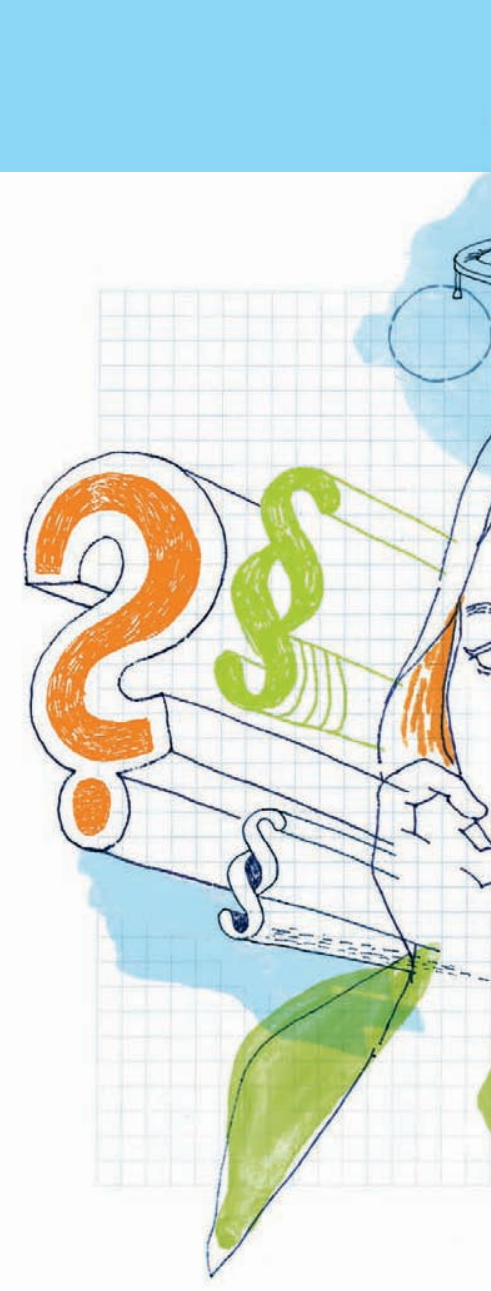

Die Rechtsfrage

„ Ich würde gerne Akupunktur für Selbstzahler

anbieten. Stimmt es, dass mir das als Physio-

therapeutin aufgrund der Rechtslage nicht erlaubt

ist? Im Gegenzug darf ein Tätowierer eine invasive

Technik ohne jeglichen Qualifikationsnachweis

anwenden. "

Ina Koetz, Physiotherapeutin aus Osnabrück

\section{Die Antwort unseres Experten}

Bevor Sie Selbstzahlerleistungen anbieten, müssen Sie stets zwei Fragen beantworten: Dürfen Sie bestimmte Leistungen ohne Weiteres erbringen oder ist hierfür eine gesonderte Erlaubnis wie die Heilpraktikererlaubnis notwendig? Zudem sollten Sie klären, ob gesetzliche oder private Krankenversicherungen für die Kosten aufkommen. Daneben gilt es, sich darüber klarzuwerden, wie man bestimmte Leistungen steuerlich behandeln muss, vor allem im Hinblick auf die Umsatzsteuer.

Bei der Akupunktur scheitert eine Anwendung als Therapeut bereits auf der ersten Stufe, denn die Akupunktur stellt eine Heilbehandlung dar. Dies ist bereits gerichtlich entschieden. Therapeuten dürfen Heilbehandlungen nur als Ärzte oder Heilpraktiker durchführen. Berufsspezifische Heilleistungen hingegen, zu denen die Akupunktur nicht zählt, dürfen sie aufgrund einer ärztlichen Verordnung oder der Verordnung eines Heilpraktikers ausführen. Die Erbringung von Heilleistungen unter Verstoß gegen das Heilprak- tikergesetz stellt in jedem Fall eine Straftat dar.

Der scheinbare Wertungswiderspruch zu einem Tätowierer ergibt sich daraus, dass Tätowierer keine Heilbehandlungen anbieten. Für sie gilt das Heilpraktikergesetz nicht. Heilbehandlungen sollen die Gesundheit fördern. Daher ist hier ein besonderes öffentliches Regelwerk einschlägig, um die Volksgesundheit zu schützen. Entschließt sich jemand, eine Heilbehandlung wahrzunehmen, soll zumindest kein weitergehender Schaden eintreten. Entschließt sich jemand jedoch, sich tätowieren, piercen, auspeitschen zu lassen oder mit einem Amateurboxer in den Ring zu steigen, so ist er in seiner Entscheidung frei. Willigt er in die ihm bevorstehenden Körperverletzungen ein, werden keine Straftatbestände erfüllt.

Eine Heilpraktikererlaubnis hilft daher im Gesundheitswesen über die besonderen gesetzlichen Hürden hinweg. Ohne Heilpraktikererlaubnis und/oder Verordnung darf man keine Selbstzahlerleistungen im
Heilbehandlungsbereich erbringen. Dies gilt für die Akupunktur ebenso wie für Physiotherapie oder Manuelle Therapie. Bei den beiden letztgenannten Behandlungen würde allerdings das Vorliegen einer Verordnung ausreichen. Dr. Philipp Groteloh

\section{$\exists$ Wirft auch Ihr Berufsalltag rechtliche Fragen auf? Dann schreiben Sie an Simone.Gritsch@thieme.de.}

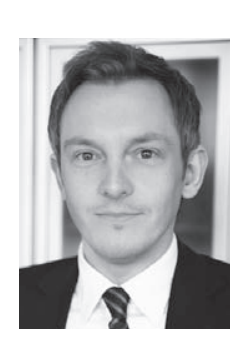

Dr. Philipp Groteloh ist seit 2007 Rechtsanwalt und seit 2012 Fachanwalt für Verwaltungsrecht. 